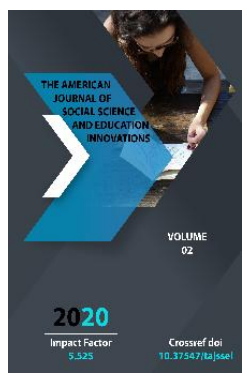

\title{
Contents Of Educational Process For Students Health: Actual Causes And Factors
}

Journal Website: http://usajournalshub.c om/index,php/tajssei

\author{
Ilhom Mattiev \\ Senior Lecturer (PhD) of the Department of Language Teaching, Samarkand Institute of \\ Economics and Service, Uzbekistan
}

\section{ABSTRACT}

In this article is described the development and implementation of health care technologies into the education system, the need for health education pedagogy is becoming ever more relevant global health pedagogy, its technology, methodology for its implementation into the educational process and its principles, the development of methods, tools and approaches which are widely studied.

\section{KEYWORDS}

Health care, educational process, actuality, protection, discipline, rights, confidence, logical, consistent, implementation.

\section{INTRODUCTION}

Among the up-to-date requirements for the education system, it is becoming increasingly important to implement health promotion activities and to provide appropriate pedagogical conditions. Today, educational goals require that students pay special attention [3,4].

That is why the development and implementation of health care technologies in the education system, the demand for pedagogy for health care is becoming ever more urgent. Problems of world health pedagogy, its technology, methodology for its implementation in educational process, development of principles, methods, tools and ways of ensuring student health in educational process are widely studied $[1,9]$. There is a set of issues that need to be solved theoretically and practically for the development of health education pedagogy, which includes the following questions:

$\checkmark$ How the educational process and its socio-pedagogical conditions can be 
detrimental and threatening to the health of students

$\checkmark$ What conditions of the educational process can provide and protect the health of students in every way possible

$\checkmark$ The educational process consists of a set of aspects that the student can maintain and improve his or her health and development process.

$\checkmark$ These issues and questions involve a set of pedagogical efforts that must and should be undertaken during the periods of education, such as organizing, conducting and managing the learning process.

$\checkmark$ For example, the factors that may be detrimental to a student's health during the educational process can be identified as follows:

$\checkmark$ Exceeding the required quantity, quantity, and scope of academic subjects identified during the semester

$\checkmark$ Exceeding the required items for the day, their quantity, size and scope, as well as their intellectual, physical, and psychosocial impact

$\checkmark$ Overload of student self-study materials over the level of complexity and demand

$\checkmark$ Excessive complexity and abundance of learning materials

$\checkmark$ Wide range of authoritarian methods in the organization of the educational process, successive consecutive visits of several authoritarian training sessions per day

$\checkmark$ Monitoring of student knowledge and monitoring of the course is a frequent occurrence of stressful situations, a systematic, preventive, non-scheduled work or failure to monitor student knowledge.

$\checkmark$ The biggest worry in the face of poor student evaluation is the fear of what will happen next $\checkmark$ Loss of self-esteem, anxiety and selfconfidence, when a student violates various requirements of the learning process, discipline, attendance, learning, participation in activities

$\checkmark$ Displays of the student's overall fatigue symptoms during the training session, that is, his or her neglect of the subject matter, the lack of focus on the student's mind, and his or her thinking.

Consequently, these situations are specific aspects of a student's overall health, which naturally require specific and targeted efforts to promote student health.

A skilled and experienced teacher can immediately diagnose symptoms of external fatigue in their student:

$\checkmark$ Inability of the student to sit quietly in his seat, not to be comfortable, to place his head in his hands, to lie on the table with his head, to chew a pen, to hang his legs and arms around his body, to press the table;

$\checkmark$ To stretch, to stretch from time to time, to stretch;

$\checkmark \quad$ Shake and shake hands;

$\checkmark$ To grow old, to lie down, to lie down or to stretch;

$\checkmark$ Close your eyes, fall asleep;

$\checkmark$ A naked eye, a reactionless, meaningless look;

$\checkmark$ Rearranging the items on the table, stacking them from one position to another;

$\checkmark$ The student's emotional and mental outbursts, not in the classroom, but completely closed;

$\checkmark$ A student's ability to talk and talk around with everyone;

$\checkmark$ A sharp increase in student responses;

$\checkmark$ The student does not immediately understand the question asked by the teacher; 
Student's inability to find the right answer to the question right away;

$\checkmark$ A student can quickly look at his watch, count the minutes, and look forward to the end of the lesson.

Consequently, the protection and preservation of student health begins with the creation of a common educational and educational process, with all the factors related to this process, how the timetable is compiled, the proper sanitaryepideomological condition of the classrooms, the air, humidity, heat and other necessary parameters. Taking into account the competence and specificity of teachers, it is important to take into account all of them. In order for the student to be able to fully meet the educational needs of the student throughout the day, he / she needs to be able to organize continuity and continuity, which is a set of logical sequences based on games and actions.

The above characteristics show that a student is tired during a particular session, bored with the subject, and has left his / her medical and psychological education. If these situations and situations occur on a regular basis, it will not only have a negative impact on the student's learning effectiveness but also on his or her health.

In this daily learning process, a set of targeted efforts to address the health of the student creates pedagogical principles aimed at maintaining student health. They are:

1. The principle of physical, psychological, medical, mental harm and harm to student health [2];

2. To set up a set of planned and ultimately targeted actions at the educational institution aimed at maintaining student health;

3. The principle of ensuring the unity and integrity of all areas, areas of health care, including medical, physical-hygienic, psycho-psychological, mental, intellectual and spiritual-ideological health, established in an educational institution [5];

4. Organization and maintenance of a process of understanding, acceptance, and transformation into a life-changing position in continuity and continuity of health at all stages of the educational process [3,6];

5. Establishing the subject-subject relationship with the student, setting an example for it, and achieving a holistic, functional life with ideas, ideas and ideas aimed at maintaining health.

6. The principle of comprehensive impact on student health, based on the diversity and interactivity of pedagogical forms, tools and methods, in order to develop student-centered thinking;

7. The principle of taking into account the specifics of the student in terms of individual and age differentiation and, accordingly, the organization of the educational process, ie the principle of harmonization of consciousness, thinking, and practical efforts for student health;

8. Integrity of strategies for organizing student workloads for the purpose of health protection for the formation and development of a student in a pedagogical environment focused on health, the principle of their integrity.

Pedagogical efforts to promote health in the educational institution involve complexity, unity and integrity of directions, purposefulness, diversity of forms, means and methods, strict standards of living position, requirements and criteria of the student. The use of the same pedagogical conditions is the main factor of pedagogical effectiveness 
Naturally, the presence of the following conditions increases the chances of pedagogical achievement:

? Excessive workloads and requirements of the student's medical and physical conditions, as well as excessive fatigue, exhaustion, violation of the boundaries of his mental state;

$\checkmark$ Organization and purposeful carrying out regular medical, psychological, psychological and physical preventive measures with the student;

$\checkmark$ To provide the necessary sanitary-andepidemiologic conditions for the correct nutrition of the student;

$\checkmark$ Provide and strengthen the work of protecting students from various diseases that are directly related to the educational and educational process;

$\checkmark$ The spread of various harmful habits among students, such as drug addiction, spa use, sexually transmitted diseases, AIDS, alcoholism, smoking, toxicomania;

$\checkmark$ Formation of students' knowledge, skills and skills in health education, as well as their general culture of teaching, competence of teachers in the modern pedagogical and medico-physical level, and their current health promotion. Providing them with innovative teaching technologies and appropriate prerequisites for doing so.

Establish and maintain a coherent, purposeful pedagogical environment for parents to organize educational activities aimed at protecting and protecting the health of students with public sector organizations and civil society institutions [7].

In most cases, due to the various ORVI and inflammatory diseases in the students during the winter season, the necessary conditions in the classroom are inadequate. For example, the temperature in the classroom will either decrease or the room will be cold, or the room temperature will be too high and the room will warm up dramatically. Either way, the health of the students is present in the threat process. Elvizak, sweating in cold weather, or wearing sweatshirts based on attending a classroom without wearing special sports uniforms, going to the next classroom, and the room being cold during this time, naturally causes a variety of colds. For example, pulmonary inflammation, chronic bronchitis, renal inflammation, and bladder inflammation are among these effects.

After a few hours of classroom training, the ventilation is dehydrated, which means that many airborne viruses, microbes, bacteria, and bacteria in the respiratory system can be absorbed by the air, thus preventing most diseases. After all, small pains in the throat, dryness of the throat, and occasional coughing may be the reason for the unexplained, dehydrated air in the auditorium. Consequently, the air in the auditorium should be clean, light, oxygen-saturated, and not dry. It should also be taken into account that student eye redness, eyelashes, and itching may actually be related to the air of the auditorium, or to the excessive use of various information gadgets, including cell phones, laptops, and tablets. Because regular, continuous exposure to light that is so bright for a long time, including computer light, can weaken the eyes and even cause inflammation of the blood vessels.

Consequently, educators who are competent in health care pedagogy today should naturally be able to properly analyze their students' medical emotional and physiological conditions and encourage them to take responsibility for their own health at regular intervals [8].

In this context, the organization of the learning process requires the following: 
$\checkmark$ Ability to organize the educational process in the context of health care against didactogeny ;

$\checkmark$ To be able to organize the educational process without neglect of human health;

$\checkmark$ Require teachers to know and apply pedagogical technologies in health care, and, if necessary, to improve their skills in this regard:

$\checkmark \quad$ Making health education a top priority in the education and upbringing process;

$\checkmark$ To prevent students' ignorance and poor culture on the purpose, essence and methods of health care in the pedagogical process, to create special faculties, lesson hours, and constantly improve the content of education;

$\checkmark$ Necessary infrastructure for continuous provision of teachers and students health, including dependence on specialized polyclinics, regular free examinations, provision of special recreation areas, and prevention of their health loss;

$\checkmark$ To require teachers to have sufficient knowledge, skills and abilities in health education pedagogy within their professional competence.

$\checkmark$ As part of the pedagogy of health care, it is necessary to study the new aspects of human relations, in particular the emphasis on the teacher's ability to have sufficient tolerance, leadership, sense of humor and humor.

Thus, the education and upbringing of students in a higher education environment $[10,11]$ is a process of education and upbringing that requires complex pedagogical conditions and its essence is based on principles of health pedagogy.
1. Ahramenko E. V. Zdorovesberegayushchie technology: read more // - 2015. - No. 24. - p. 910912.

2. Abdurahimova F.Y. Pedagogical bases of preparation of girls for family on the basis of healthy lifestyles in the mahalla. Ped.f .... diss. autoreferencing. $-\mathrm{T}$.: 2007, 23

3. Jamoldinova O.R. Improvement of pedagogical mechanisms of the principles of continuity and continuity in the development of a healthy culture of youth. Ped. science doc ..... diss. author - Tashkent: 2015, - 86 p.

4. Musurmonova O., Abdurakhimova FY Healthy lifestyles of girls in the neighborhood. -T .: "Uzbekistan", 2007. -168 b .

5. Musurmonova O., D. Sharipova, S. Akhmedova. Healthy Generations of Family, Women T.: 2007, 119 b .

6. Nishonova S. Healthy Lifestyle. // Continuing education. 2007, No. 6, -B. 77-83

7. Riskulova KJ Partnership of NGOs in the formation of a healthy culture of youth. Ped. .... diss. auto $-\mathrm{T}$.: 2010. — B. 27

8. Umatkulov TM Pedagogical bases of preparing teachers for protection of students' health in the course of training. Ped. science. name dis. autoref. - T., 2003. - 20 b .

9. Urazalieva I. R., Murotova G. S. Поддержка и среднее здоровья променения в первичном здравоохранения // Молодой ученый. - 2015. - No. 23. - p. 384-386.

10. Sharipova DD, Musurmanova O., Toirova M. Format for zdorovogo image - Tashkent: UzGIFK, 2005. -S. 7. (-179 p.) 
Doi: https://doi.org/10.37547/tajssei/Volume02Issue08-71

11. Sharipova D.vaboshk.Health. $-T$ :

Polispectekt LLC, 2006, - 112b. 